Marquette University

e-Publications@Marquette

Physics Faculty Research and Publications

Physics, Department of

9-1-2010

\title{
Controlling Individual Domain Walls in Ferromagnetic Nanowires for Memory and Sensor Applications
}

\author{
Andrew Kunz \\ Marquette University, andrew.kunz@marquette.edu \\ Sarah C. Reiff \\ Jonathan D. Priem \\ Eric W. Rentsch
}

Accepted version. Published as a part of the conference 2010 ICEAA Offshore/IEEE Xplore, 2010: 248-251. DOI.

(C) 2010 IEEE. Reprinted, with permission, from Andrew Kunz, Sarah C. Reiff, Jonathan d. Priem, Eric W. Rentschle, Controlling individual domain walls in ferromagnetic nanowires for memory and sensor applications, Proceedings of 2010 ICEAA Offshore/IEEE Xplore, September 2010.

This material is posted here with permission of the IEEE. Such permission of the IEEE does not in any way imply IEEE endorsement of any of Marquette University's products or services. Internal or personal use of this material is permitted.

However, permission to reprint/republish this material for advertising or promotional purposes or for creating new collective works for resale or redistribution must be obtained from the IEEE by writing to pubs-permissions@ieee.org. By choosing to view this document, you agree to all provisions of the copyright laws protecting it. 


\title{
Controlling Individual Domain Walls in Ferromagnetic Nanowires for Memory and Sensor Applications
}

\author{
Andrew Kunz \\ Physics Department, Marquette University, \\ Milwaukee, WI \\ Sarah C. Reiff \\ Physics Department, Marquette University, \\ Milwaukee, WI \\ Jonathan D. Priem \\ Physics Department, Marquette University, \\ Milwaukee, WI \\ Eric W. Rentsch \\ Physics Department, Marquette University, \\ Milwaukee, WI
}

Controlled motion of $180^{\circ}$ and $360^{\circ}$ domain walls along planar nanowires is presented. Standard Landau - Lifshitz micromagnetic modeling has been used to simulate the response of the domain walls to the application of an external magnetic field. A $180^{\circ}$ wall is quickly and easily moved with the application of an applied. field along the axis of the wire but a $360^{\circ}$ domain wall is stationary in the same case. An oscillatory applied field can be used to continually move the wall along the wires axis. The speed at which the $360^{\circ}$ domain wall is found to be several times slower than a similar $180^{\circ}$ domain

Proceedings of 2010 ICEAA Offshore/IEEE Xplore, (September 2010): pg. 248-251. DOI. This article is ( Institute of Electrical and Electronics Engineers (IEEE) and permission has been granted for this version to appear in $\underline{\text { e- }}$ Publications@Marquette. Institute of Electrical and Electronics Engineers (IEEE) does not grant permission for this article to be further copied/distributed or hosted elsewhere without the express permission from Institute of Electrical and Electronics Engineers (IEEE). 
wall and is limited by interaction between the magnetization of the domain wall and the external field.

\section{Section 1: Introduction}

A magnetic domain wall is the transition region between oppositely magnetized domains. This transition region can be put into motion with the application of an external magnetic field or with a spin-polarized current via a spin-torque effect ${ }^{1,2}$. Each driving mechanism has its advantages over the other but in principle the dynamics of the moving wall are the same and ultimately a combination of the two effects is likely to be necessary. Several spintronic devices in logic, recording, and sensing have been proposed which utilize the motion of a domain wall along the axis of a thin, narrow nanowire to transmit or store information ${ }^{3,4}$. The realization of these devices depends in part on the ability to control the location of the domain wall in the wire.

In a thin enough nanowire there is essentially one type of domain wall, a transverse or $180^{\circ}$ domain wall where the magnetization rotates in the plane of the wire as it transitions from one direction to the other as shown at the top of Figure 1 [5]. The bottom image shows two transverse walls which have been pushed together to create a full rotation of the magnetization. This extremely stable structure is called a $360^{\circ}$ domain wall and it considered a transition between two aligned domains. Arrows representing the direction of the magnetic moments are included in Figure 1 to show how the transition occurs. The red and blue shading correspond to the direction of the long axis magnetization and the scheme remains the same throughout this manuscript.

Controlling a domain wall requires involves both moving the wall and stopping it. For device operation it is preferential to move the wall quickly. The $180^{\circ}$ domain wall is easily, and quickly, moved with the application of an external magnetic field oriented along the long axis of the wire. The wall moves as the domain in the direction of the applied field grows at the expense of the oppositely magnetized domain, which leads to an overall reduction in Zeeman energy. A $360^{\circ}$ domain wall is not easily moved however. When a field is applied along the main magnetization direction, to the right in Figure 1, the left and right

Proceedings of 2010 ICEAA Offshore/IEEE Xplore, (September 2010): pg. 248-251. DOI. This article is (C) Institute of Electrical and Electronics Engineers (IEEE) and permission has been granted for this version to appear in ePublications@Marquette. Institute of Electrical and Electronics Engineers (IEEE) does not grant permission for this article to be further copied/distributed or hosted elsewhere without the express permission from Institute of Electrical and Electronics Engineers (IEEE). 
walls remain stationary, essentially pushing up against each other. The robustness of the $360^{\circ}$ wall to applied fields is a desired feature for recording information therefore moving the wall to a desired location is critical. If the field is applied in the reverse direction, to the left, the walls separate but they move with the same speed so the "center" of the overall transition region remains stationary. A current might be useful in this case as it has been shown that currents move domain walls in the same direction, although typically an order of magnitude slower than a field moves the wall. Here we present a technique for moving the $360^{\circ}$ domain wall with applied fields with minimum speeds equivalent to that found in fast current driven cases ${ }^{1}$.

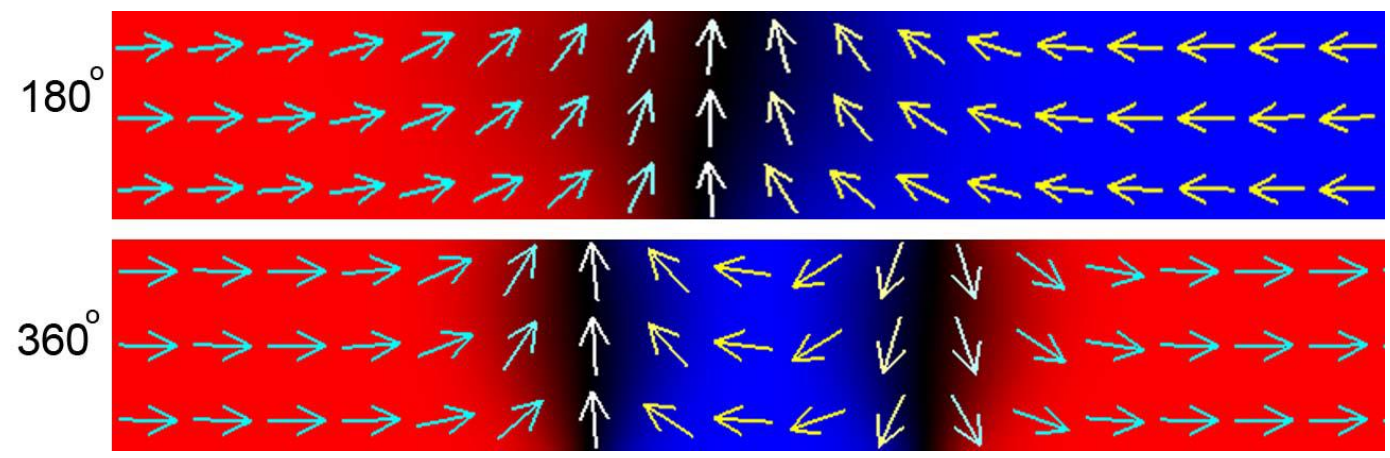

Figure 1: Representations for the magnetic moments of a $180^{\circ}$ and $360^{\circ}$ domain wall in a $100 \mathrm{~nm}$ wide wire

Once a simple transverse wall is in motion there are several techniques available for stopping it. Most techniques rely on a change to the physical shape or magnetic structure of the wire, often a notch or protrusion in the wire itself 8,9 . Because these artificial defects must be added ahead of time, during the manufacturing of the wire, precision control of the domain walls can be obtained but there is no possibility of changing the trapping locations. Additionally, a trapped domain wall is often difficult to release, requiring large fields or currents to put the wall into motion again ${ }^{10}$. Additional control of domain wall pinning locations could be realized if the pinning sites could be moved as opposed to set when built. Recently it was proposed that domain walls could be used as traps for other domain walls in neighboring wires ${ }^{11,12}$. The domain walls would couple together across the wires and could allow for an additional degree of control if the $360^{\circ}$ walls could be reliably moved. In this work we present our Proceedings of 2010 ICEAA Offshore/IEEE Xplore, (September 2010): pg. 248-251. DOI. This article is (C) Institute of Electrical and Electronics Engineers (IEEE) and permission has been granted for this version to appear in $\underline{\mathrm{e}}-$ Publications@Marquette. Institute of Electrical and Electronics Engineers (IEEE) does not grant permission for this article to be further copied/distributed or hosted elsewhere without the express permission from Institute of Electrical and Electronics Engineers (IEEE). 
technique for controlling the location of a $360^{\circ}$ domain wall. Our technique controls the location of the wall by systematically controlling the external field pulse durations and directions used to move the wall.

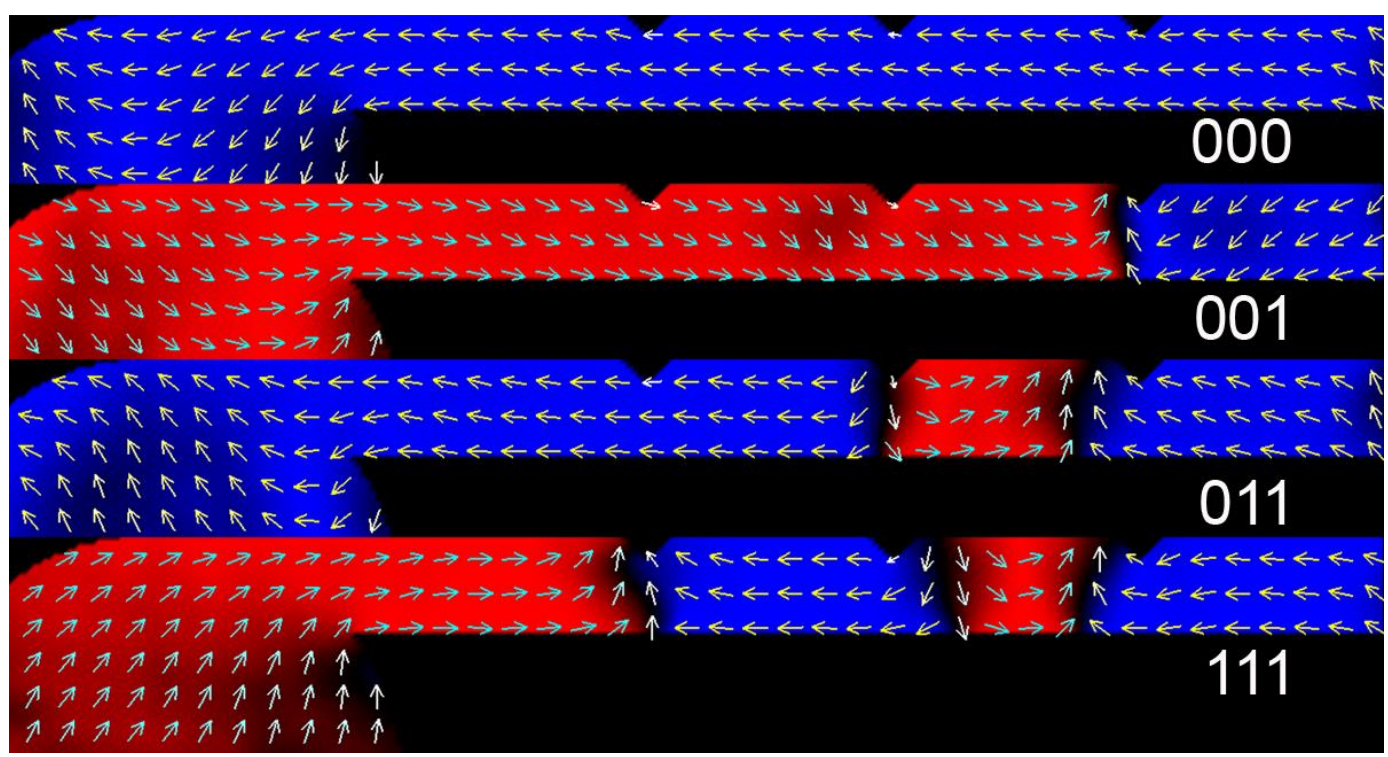

Figure 2: Time lapse sequence of domain walls being injected and trapped in a wire with magnetic fields.

\section{Section 2: Simulation Details}

We simulate the motion of a domain wall with standard threedimensional micromagnetic simulation. The simulations follow the standard Landau-Lifshitz equation of motion for the magnetic moments $m$ in the wire

$$
\frac{\partial \vec{m}}{d t}=-\gamma \vec{n} \times H-\frac{\alpha \gamma}{M_{S}} \vec{m} \times(\vec{m} \times \vec{H})
$$

where $y$ is the gyromagnetic ratio, $M_{s}$ is the saturation magnetization and $H$ is the total magnetic field acting on a magnetic moment ${ }^{13}$. The materials parameters are for permalloy. The simulated wires have a length of 10 microns and a $100 \times 5 \mathrm{~nm}^{2}$ rectangular cross-section. The wire is discretized into identical cubes, no larger than $5 \mathrm{~nm}$ on edge and integrated with a 4th order predictor corrector technique with a

Proceedings of 2010 ICEAA Offshore/IEEE Xplore, (September 2010): pg. 248-251. DOI. This article is (C) Institute of Electrical and Electronics Engineers (IEEE) and permission has been granted for this version to appear in ePublications@Marquette. Institute of Electrical and Electronics Engineers (IEEE) does not grant permission for this article to be further copied/distributed or hosted elsewhere without the express permission from Institute of Electrical and Electronics Engineers (IEEE) 
simulated integration time step of less than a picoseconds. The magnetic damping parameter is $\alpha=0.008$.

To put the walls in motion magnetic fields are applied along the long axis of the wire. We keep the moving wall field strength below the so-called Walker breakdown field to maintain the domain walls of a known shape and because this is the field range for which the walls move the quickest.

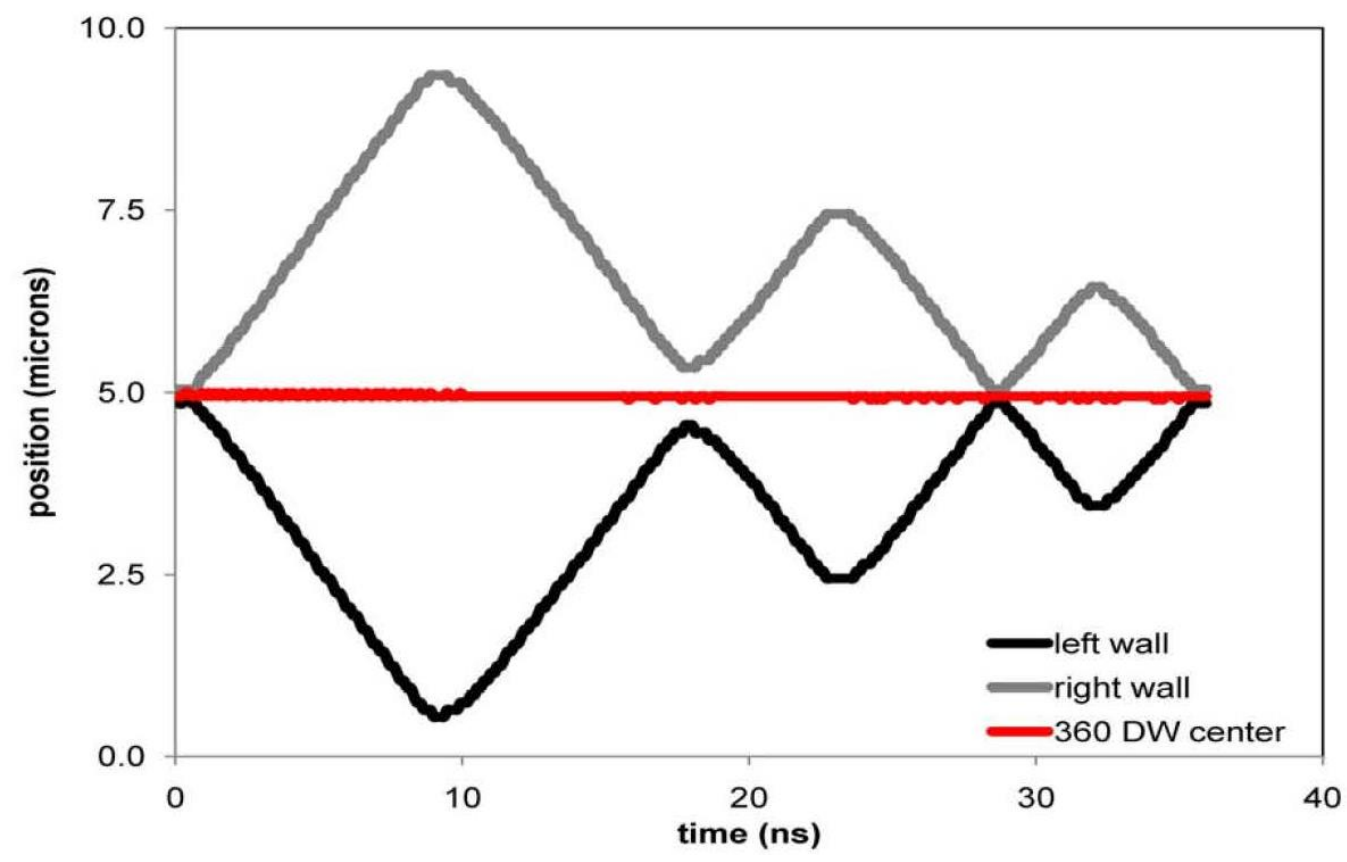

Figure 3: Position of the $360^{\circ}$ wall components when moved by a longitudinal field. The composite walls center is stationary.

\section{Section 3: Domain Wall Control}

\section{$3.1180^{\circ} \mathrm{Walls}$}

A time lapse sequence of a series of domain walls which were injected, transmitted, and trapped is shown in Figure 2 by using only magnetic fields ${ }^{14}$. The combination of effects described above for transverse walls shows how these ideas come together to demonstrate the ability to write information. First a domain wall is injected into the Proceedings of 2010 ICEAA Offshore/IEEE Xplore, (September 2010): pg. 248-251. DOI. This article is ( Institute of Electrical and Electronics Engineers (IEEE) and permission has been granted for this version to appear in $\underline{\mathrm{e}}-$ Publications@Marquette. Institute of Electrical and Electronics Engineers (IEEE) does not grant permission for this article to be further copied/distributed or hosted elsewhere without the express permission from Institute of Electrical and Electronics Engineers (IEEE). 
wire from the pad on the left. The wall is then quickly driven along the length of the wire until it is trapped at a notch. The elapsed time between "0 00 " and " 001 " was under 2 ns. The now trapped wall is stationary as the subsequent domain walls are injected and moved in to location. A three bit sequence, in Figure 2 a " 1 " or a " 0 " depends on the presence of a domain wall at a trapping point, has 8 possible states so this structure represents the minimum necessary for writing information quickly and reliably. Four of the eight representations are shown. The final " 111 " sequence was written in under 6 ns.

\section{$3.2360^{\circ} \mathrm{Walls}$}

Stopping a $360^{\circ}$ domain wall is as easy as letting the two transverse walls collide under a compressive field (field that moves the walls toward each other). The two colliding transverse walls couple together to create a robust $360^{\circ}$ domain wall. Figure 3 shows the difficulty in moving a $360^{\circ}$ domain wall. The plot shows the position of the left and right walls as a function of time as a magnetic field is applied along the long axis of the wire. Initially the field drives the walls quickly apart. When the field is later reversed, the domain walls turn around and move together.

Proceedings of 2010 ICEAA Offshore/IEEE Xplore, (September 2010): pg. 248-251. DOI. This article is (C) Institute of Electrical and Electronics Engineers (IEEE) and permission has been granted for this version to appear in $\underline{\mathrm{e}}-$ Publications@Marquette. Institute of Electrical and Electronics Engineers (IEEE) does not grant permission for this article to be further copied/distributed or hosted elsewhere without the express permission from Institute of Electrical and Electronics Engineers (IEEE). 

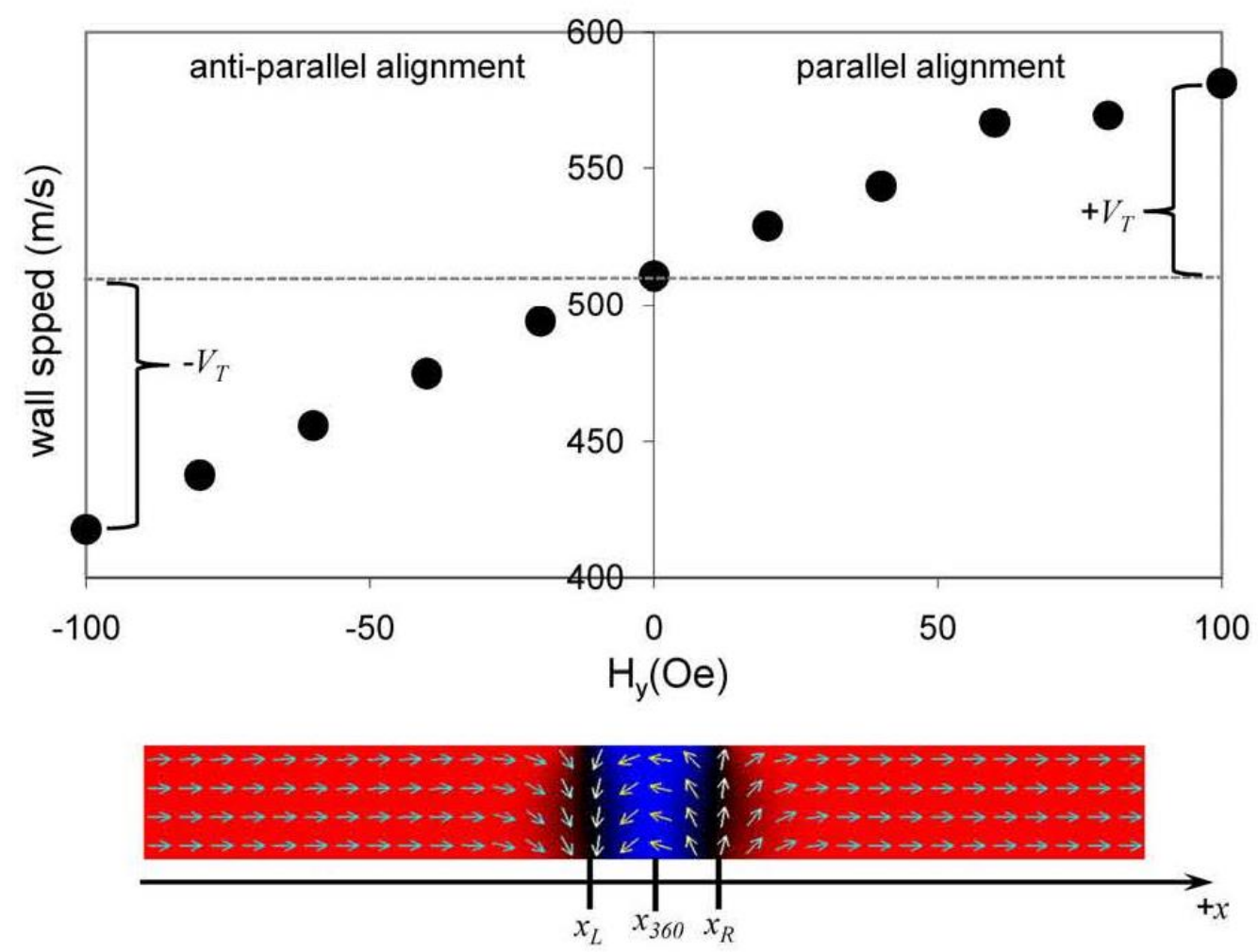

Figure 4: There is an asymmetry in the speed of a domain wall when transverse in-plane fields are used with longitudinal driving fields. The effect depends on the relative alignment of the transverse field and the magnetic moments in the domain wall.

The average location (called the 360 DW center) is shown to be essentially constant for the entire trial. The reason the wall center is stationary is that the left and right walls have the same speed and because they travel in opposite directions the velocity is zero.

An extra component of magnetic field applied in the plane of the wire but perpendicular to the long axis of the wire has previously demonstrated to significantly change the speed of a domain wall based on the relative alignment of the transverse field and magnetic moments in the domain wall ${ }^{15,16}$. Figure 4 shows that when the transverse field is positive (parallel to the magnetization of the right wall) the wall travels faster. The opposite is true when the two are anti-aligned. The effect is almost linear such that for a given

Proceedings of 2010 ICEAA Offshore/IEEE Xplore, (September 2010): pg. 248-251. DOI. This article is (C) Institute of Electrical and Electronics Engineers (IEEE) and permission has been granted for this version to appear in $\underline{\mathrm{e}}-$ Publications@Marquette. Institute of Electrical and Electronics Engineers (IEEE) does not grant permission for this article to be further copied/distributed or hosted elsewhere without the express permission from Institute of Electrical and Electronics Engineers (IEEE). 
transverse field strength that each walls speed changes by the same magnitude $V_{T}$. This allows for the systematic control of a $360^{\circ}$ domain wall as shown in Figure 5 . Initially, along path $A$, a magnetic field is applied along the long axis of the wire to separate the two walls and a transverse field is used to move the right wall more quickly than the left wall. The fields are reversed causing the walls to move back toward each other. This time the reversal of the transverse field, along path $B$, moves the left wall quicker than the right so that when the two walls approach each other at $\mathrm{C}$. This process is repeated until the wall has been moved a 2.5 microns. The average speed of the domain wall center is roughly $85 \mathrm{~m} / \mathrm{s}$. This is about an order of magnitude less than the $500 \mathrm{~m} / \mathrm{s}$ a single transverse wall moves but it is consistent to the maximum speed observed for a single wall driven by an electric current and the first report of moving a $360^{\circ}$ domain wall with applied fields.

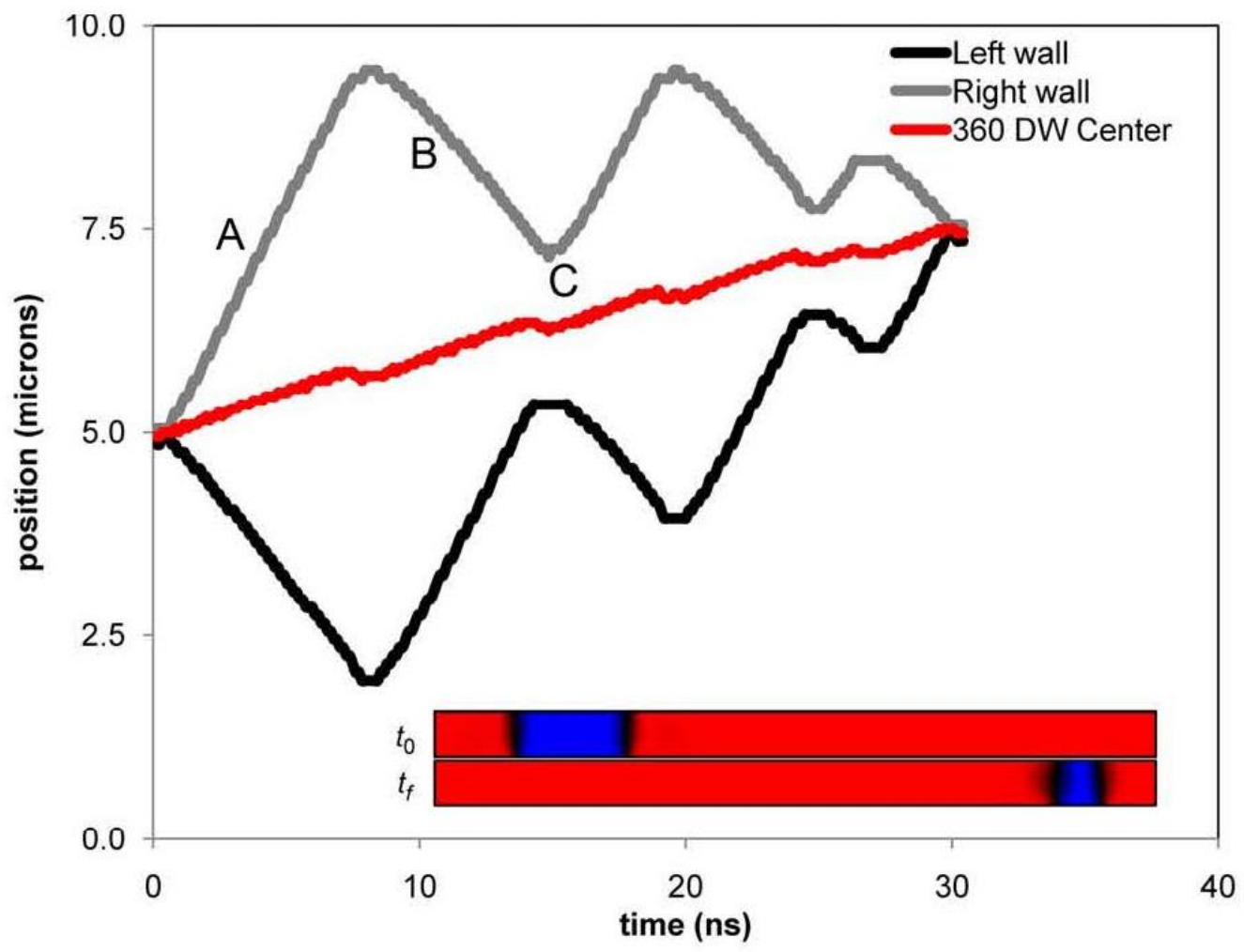

Figure 5: Transverse fields are used to move 3600 domain walls significant distances by oscillating the field components. The wall averages $85 \mathrm{~m} / \mathrm{s}$.

Proceedings of 2010 ICEAA Offshore/IEEE Xplore, (September 2010): pg. 248-251. DOI. This article is (C) Institute of Electrical and Electronics Engineers (IEEE) and permission has been granted for this version to appear in $\underline{\mathrm{e}}-$ Publications@Marquette. Institute of Electrical and Electronics Engineers (IEEE) does not grant permission for this article to be further copied/distributed or hosted elsewhere without the express permission from Institute of Electrical and Electronics Engineers (IEEE). 


\section{Section 4: Discussion}

The maximum speed of a $360^{\circ}$ domain wall is a function of the transverse field. Larger transverse fields should lead to faster overall speeds. As shown in Figure 4 we define the center of the domain wall, $x_{360}$, to be the average position of the left, $x_{L}$, and right, $x_{R}$. walls

$$
x_{360}=\frac{x_{L}+x_{R}}{2}
$$

The position of each wall as a function of time is $x(t) R, L=\nu R, L t$ where the subscripts correspond to the left and right walls individually. When a transverse field is applied parallel to the moments in the right wall (anti-parallel to the left) the velocity of each wall changes in proportion by

$$
\begin{aligned}
& \nu_{R}=\nu_{0}+V_{T} \\
& \nu_{L}=-\left(\nu_{0}-V_{T}\right)=-\nu_{0}+V_{T} .
\end{aligned}
$$

Where $v_{0}$ is the speed with no transverse field and $V_{T}$ is the speed change due to the transverse field. This means that the domain wall center is located at

$$
x_{360}=\frac{\left(-v_{0}+V_{T}\right) t+\left(v_{0}+V_{T}\right) t}{2}=V_{T} t
$$

When the field are reversed the velocities of the walls change in magnitude and direction such that

$$
\begin{gathered}
\nu_{R}=-\left(\nu_{0}-V_{T}\right)=-\nu_{0}+V_{T} \\
\nu_{L}=\nu_{0}+V_{T}
\end{gathered}
$$

the center of the domain wall continues to move forward with the speed gained by the application of the transverse field

$$
x_{360}=\left(\frac{\left.v_{0}+V_{T}\right) t+\left(-v_{0}+V_{T}\right) t}{2}=V_{T} t .\right.
$$

Proceedings of 2010 ICEAA Offshore/IEEE Xplore, (September 2010): pg. 248-251. DOI. This article is (C) Institute of Electrical and Electronics Engineers (IEEE) and permission has been granted for this version to appear in $\underline{\mathrm{e}}-$ Publications@Marquette. Institute of Electrical and Electronics Engineers (IEEE) does not grant permission for this article to be further copied/distributed or hosted elsewhere without the express permission from Institute of Electrical and Electronics Engineers (IEEE) 
This simple calculation shows that the $360^{\circ}$ wall cannot move without the transverse fied. Additionally it is instructive to compare the results of the simulation with this simple calculation. We measure $V_{T}=110 \mathrm{~m} / \mathrm{s}$ in this trial, whereas we measure a speed for the domain wall of $85 \mathrm{~m} / \mathrm{s}$ which is in good agreement. The bulk of the difference comes from the reversal of the domain walls as noticed in Figure 5. When the fields are reversed the walls stop and turn around slowing the overall progress. The simple calculation above represents the maximum speed a $360^{\circ}$ domain wall could move which will be slowed by the necessary field reversals. In a long wire the reversals could be minimized because there would be more room for the walls to move, whereas in our 10 micron simulation we had to reverse the fields to keep the walls from leaving the ends of the wire.

\section{Section 5: Conclusion}

Magnetic fields are used to quickly move and control the location of $360^{\circ}$ domain walls in thin, narrow nanowires. A $360^{\circ}$ domain wall moves with a maximum speed determined by the strength of a transverse field which is necessary to propagate the wall. This speed is slower than typically found for a $180^{\circ}$ domain wall but still fast when compared to similar efforts using electric currents as the driving mechanism. The precise location of the $360^{\circ}$ domain wall can be controlled without making physical changes to the wire. Instead controlling the length of the field pulse determines how far the wall will move which gives an extra degree of control for tuning the wall location.

\section{Acknowledgments}

This work was supported by the National Science Foundation under Grant DMR-0706194.

\section{References}

1. Yamaguchi, A., "Real-space observation of current-driven domain wall motion in submicron magnetic wires", Phys. Rev. Lett., vol. 92, no.7, pp.077205, 2004

2. Schryer, N. L., Walker, L. R., "The motion of 180 degree domain walls in uniform dc magnetic fields", J. Appl. Phys., vol. 45, no.12, pp.5406-21, 1974

Proceedings of 2010 ICEAA Offshore/IEEE Xplore, (September 2010): pg. 248-251. DOI. This article is (C) Institute of Electrical and Electronics Engineers (IEEE) and permission has been granted for this version to appear in ePublications@Marquette. Institute of Electrical and Electronics Engineers (IEEE) does not grant permission for this article to be further copied/distributed or hosted elsewhere without the express permission from Institute of Electrical and Electronics Engineers (IEEE) 
NOT THE PUBLISHED VERSION; this is the author's final, peer-reviewed manuscript. The published version may be accessed by following the link in the citation at the bottom of the page.

3. Allwood, D. A., "Magnetic domain-wall logic", Science, vol. 309, pp.168892, 2005

4. Parkin, S. S.P., Hayashi, M, Thomas, L., "Magnetic Domain wall racetrack memory", Science, vol. 320, pp.190-194, 2008

5. McMichael, R.D., Donahue, M.J., "Head to head domain wall structures in thin magnetic strips", IEEE Trans. Magn., vol. 33, no.5, pp.4167-9, 1997

6. Castano, F.J., "Metastable staes in magnetic nanorings", Phys. Rev. B, vol. 67, no.18, pp.184425, 2003

7. Chaves-O'Flynn, G.D., "Stability of $21 n$ Domain Walls in Ferromagnetic Nanorings", IEEE Trans. Magn., vol. 46, no.6, pp.2272, 2010

8. Petit, D., Jausovec, A.-V, Read, D., Cowburn, R. P., "Domain wall pinning and potential landscapes created by constrictions and protrusions in ferromagnetic nanowires", J. Appl. Phys., vol. 103, no.11437, 2008

9. Vogel, A., "Domain-Wall Pinning and Depinning at Soft Spots in Magnetic Nanowires", IEEE Trans. Magn., vol. 46, no.6, pp.1708, 2010

10. A. Kunz, J. Priem, "Static and Dynamic Pinning Fields for Domain Walls in Ferromagnetic Nanowires", IEEE Trans. Magn., vol. 46, no.6, pp.1559, 2010 11. O'Brien, L., "Near-field interaction between domain walls in adjacent permalloy nanowires", Phys. Rev. Lett., vol. 103, pp.077206, 2009

12. Hayward, T. J., "Direct imaging of domain-wall interactions in Ni80Fe20 planar nanowires", Phys. Rev. B, vol. 81, pp.020410, 2010

13. Mircomagnetic Simulator, http://IIgmicro.home.mindspring.comv. 2.61

14. A. Kunz, S.C. Reiff, "Dependence of domain wall structure for low field injection into magnetic nanowires", Aplp. Phys. Lett., vol. 94, no.192504, 2009

15. A. Kunz, S. C. Reiff, "Enhancing domain wall speed in nanowires with transverse magnetic fields", J. Appl. Phys., vol. 103, no.07D903, 2008

16. Richter, K., Varga, R., Badini-Confalonieri, Vazquez, M., "The effect of transverse field on fast domain wall dynamics in magnetic nanowires", Appl. Phys. Lett., vol. 96, pp.182507, 2010

Proceedings of 2010 ICEAA Offshore/IEEE Xplore, (September 2010): pg. 248-251. DOI. This article is (C) Institute of Electrical and Electronics Engineers (IEEE) and permission has been granted for this version to appear in ePublications@Marquette. Institute of Electrical and Electronics Engineers (IEEE) does not grant permission for this article to be further copied/distributed or hosted elsewhere without the express permission from Institute of Electrical and Electronics Engineers (IEEE). 